\title{
The identification of SNPs in THCA synthase gene from Pakistani Cannabis
}

\author{
Saadat Alia, Mehreen Mufti ${ }^{\mathrm{b}}$, Mehwish Khan ${ }^{c^{*}}$, Ishrat Aziz ${ }^{\mathrm{d}}$ \\ ${ }^{a}$ University of Veterinary and Animal Sciences, Labore, Pakistan \\ ${ }^{b}$ Lahore University, Lahore, Pakistan \\ 'School of Biological Sciences, Quaid-e-Azam campus, University of the Punjab, Lahore, Pakistan, 54000 \\ ${ }^{d}$ University of the Punjab, Labore, Pakistan
}

Received 12th November 2018 / Accepted 2nd May 2019

\begin{abstract}
Five different isolates of Pakistani cannabis belonging to varying locations were analyzed for the presence of a reported tetrahydrocannabinolic acid (THCA) synthase marker or gene. The amplification of the marker $(12 \mathrm{~kb})$ from the five isolates confirmed them to be drug-type since the association of the marker with drug-type cannabis plants had already been established in other reports. The sequence analysis of the THCA synthase marker revealed two single nucleotide polymorphisms $(\mathrm{SNPs})$ (i.e. A851 $\rightarrow$ T851 and A883 $\rightarrow$ C883) specific to Pakistani drug-type cannabis. Furthermore, the predicted protein sequence of the isolated sequences also showed two amino acid substitutions (D284 $\rightarrow$ V284 and T295 $\rightarrow$ P295) corresponding to the identified SNPs. However, the homology based three dimensional models of the inferred proteins generated via Swiss-Model-an automated online server did not project any changes at the active sites of the enzyme (THCA) due to $\mathrm{D} \rightarrow \mathrm{V}$ and $\mathrm{T} \rightarrow \mathrm{P}$ substitutions. The two missense mutations uncovered as a result of this study may assist in distinguishing the products of Pakistani cannabis among the smuggled materials.
\end{abstract}

Keywords: Cannabis, CBGA, FAD, SNPs, THCA synthase

\section{INTRODUCTION}

Pakistan is known for being an eminent representative of the world's oldest civilization "the Indus valley". In the present research we have highlighted the specificity of Pakistani gene pool of BHANG (Cannabis sativa L.), which happens to be an ancient crop grown in Indus valley, greatly merited for the oil and fiber obtained from it. Moreover, drugs like marijuana and hashish are prepared from the inflorescence and trichomes of the dried hemp. A large number of countries have implemented stringent laws to prevent farming, importation and distribution of such drug producing crops. Unfortunately, the

* Author for correspondence: Mehwish Khan, School of Biological Sciences, Quaid-e-Azam campus, University of the Punjab, Lahore, Pakistan, 54000. Email-Mehwish_24_khan@hotmail.com. 'big road' of drug trafficking passes through Pakistan and with forensics point of view it is very important for Pakistan to have a clear position in this regard so as to facilitate the detection of illegal narcotic substances in the detained material.

Among 113 varying cannabinoids identified in hemp plant, tetrahydrocannabinol (THC) is the chief psychoactive ingredient which activates cannabinoid receptors in the human body. Therefore, the addiction-causing stupefactive cannabis contains enormous amounts of THC and is referred to as "drug-type". Conversely, the fiber-rich hemp plant possessing negligible or zero levels of THC is termed as "fiber-type". 
Since no considerable variations in the morphology of the afore-mentioned categories of the plant have been documented, a number of molecular tools have been utilized for the characterization of cannabis (Quimby et al., 1973; Small and Cronquist, 1976; Rowan and Fairbairn, 1977; Baker et al., 1982) including Inter-Simple Sequence Repeat amplification (ISSR) (Kojoma et al., 2002), Short Tandem Repeat microsatellite (STR) (Hsieh et al., 2003; Alghanim and Almirall, 2003), Amplified Fragment Length Polymorphism (AFLF) (Miller et al., 2003), 5SrRNA gene spacer region (Miyahara et al., 1998) and Random Amplified Polymorphism (RAPD) (Gillan et al., 1995; Jagadish et al., 1996; Gigliano et al., 1995; de Meijer et al., 2003). The machinery involved in the biosynthesis of $\Delta$-9tetrahydrocannabinolic acid (THCA) was unraveled in 1995 by Taura et al. In addition, the discovery of THCA synthase gene has paved the way for detailed analysis of the narcotic material in cannabis (Sirikantaramas et al., 2004).

In the present study, we used PCR to analyze variations in the cannabis isolates of specific localities (prone for illicit drug, the cannabis usage) of the Punjab, Pakistan. PCR amplification of THCA synthase gene or part of the gene was performed and the nucleotide sequences of the resulting amplicons were studied to determine genetic variations in the gene. Bioinformatic study of the available data confirmed the presence of these novel variations in the putative translated sequences of the gene.

\section{MATERIALS AND METHODS}

Plant materials. We analyzed 5 different localities for their notoriety for Bhang (cannabis) usage. One representative plant of each specific locality i.e. O (Okara), S (Sahiwal), K (Kasur), L1 (Lahore1) and L4 (Lahore 2), has been reported here (the samples are preserved at SBS herbarium under the names SBS-Pak-O-01, SBS-Pak-S-02, SBS-Pak-K-03, SBS-Pak-L1-04, SBS-Pak-L4-05, respectively). All plants used in this study were wild, the effect of environmental differences on plant growth and cannabinoid content is although an unavoidable factor but by collecting plant material from regions of Punjab, Pakistan holding relatively similar edaphic and ecological characteristics the said concern was thought to have addressed.

DNA isolation and quantification. Isolation of genomic DNA from $0.2 \mathrm{~g}$ of freshly excised 10 weeks old cannabis plant leaves was performed by a slightly improved cetyltrimethylammonium bromide (CTAB) procedure (Gilmore et al., 2003). The quantity and quality of DNA samples were analyzed using agarose gel electrophoresis. Finally, $30 \mathrm{ng} / \mu \mathrm{l}$ concentration of DNA was achieved by diluting the samples using nuclease free water.

Analysis of the sequencing result. The amplification of THCA synthase marker linked with drug-type cannabis was carried out using previously published primers (i.e. Forward primer Mh-F, 5'-AAT AAC TCC CAT ATC CAA GCA3' and reverse primer Mh-R, 5'-AGG ACT CGC ATG ATTAGT T'T-3') (Figure 1).

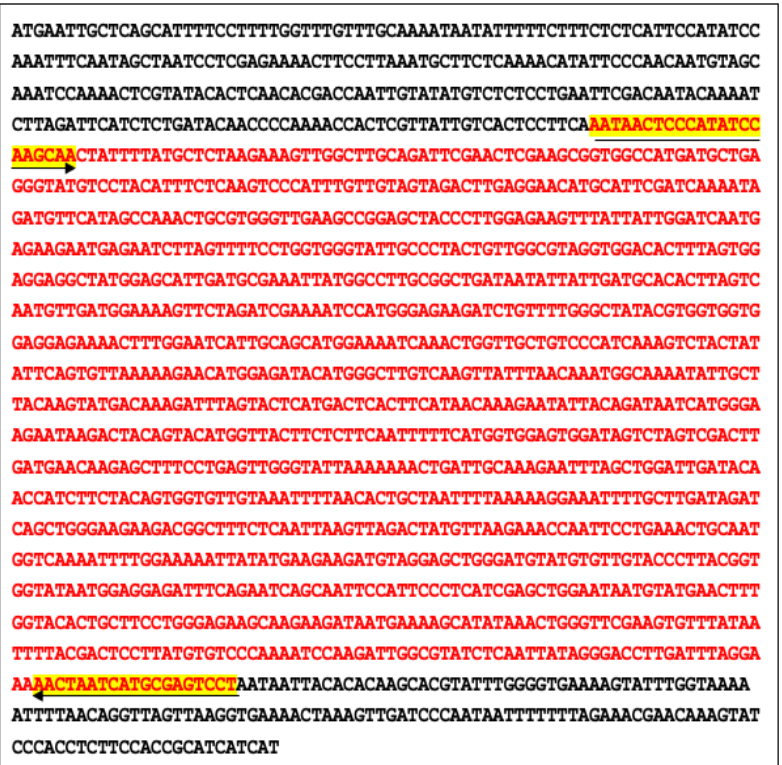

Figure 1. THCA synthase gene sequence of Cannabis sativa. Primers $\mathrm{Mh}-\mathrm{F}$ and $\mathrm{Mh}-\mathrm{R}$ are represented by arrows facing right and left, respectively. Red highlighted sequence is the amplified region

In order to perform PCR amplifications, $50 \mu \mathrm{l}$ of reaction mixtures were prepared using $60 \mathrm{ng}$ of DNA sample, $0.2 \mathrm{mM}$ dNTPs, $10 \mu \mathrm{M}$ of each primer, $2.5 \mathrm{U}$ of TrueStart ${ }^{\mathrm{TM}}$ Hot Start Taq DNA Polymerase (Thermo Scientific ${ }^{\mathrm{TM} \# \mathrm{EP} 0613), 1.5}$ 
$\mathrm{mM} \mathrm{MgCl}_{2}$ and 10X Hot Start Taq buffer. The cycling conditions were programmed as: $15 \mathrm{~min}$ of initial denaturation at $95^{\circ} \mathrm{C}$, followed by 35 consecutive cycles of denaturation $\left(1 \mathrm{~min} ; 94^{\circ} \mathrm{C}\right)$, annealing $\left(45 \mathrm{sec} ; 55^{\circ} \mathrm{C}\right)$ and elongation $(1 \mathrm{~min}$; $72^{\circ} \mathrm{C}$ ) each, ending in final elongation at $72^{\circ} \mathrm{C}$ for $10 \mathrm{~min}$. Electrophoretic analysis of the amplicons was carried out using 1\% agarose gel. The product size was $1.2 \mathrm{~kb}$.

Sequencing. The amplification products of 1.2 $\mathrm{kb}$ were gel extracted using GeneJET Gel

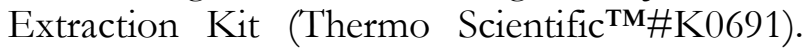
After purification, the amplified DNA segments were ligated with $\mathrm{pTZ}$ T7R/T vector from InsTAclone PCR Cloning Kit (Thermo Scientific $\left.{ }^{\mathrm{TM}} \# \mathrm{~K} 1213\right)$. The resulting recombinant plasmids were transformed into E. coli (DH5 $\alpha$ ) cells and cloned using selective media. Finally, the cloned samples were sequenced from the sequencing lab of School of Biological Sciences. Sequence alignment of our representative stocks (O, S, K, L1 and L4) was performed compared with reference sequences of published fiber and drug types (Kojoma et al., 2006) using different software i.e., DNAMAN, DNASTAR and Clustal W. Reproducibility of the results was confirmed by repeating each step at least three times.

Bioinformatic analysis. Putative protein sequences of isolated THCA synthase genes $(\mathrm{O}$, S, K, L1 and L4) as well as those of reported Drug-type (DT) and Fiber-type (FT) THCsynthase genes were predicted using an online computational translation program called ExPASy-translate tool. Multiple sequence alignment of hypothetical protein sequences was performed with the help of DNASTAR software. An online protein-modeling software SwissModel was utilized to facilitate three-dimensional homology modeling of the predicted proteins based on X-ray structures of the given template (3VTE). Since, complete sequences of DT, FT and partial sequences of the isolated samples were available; in order to model a complete structure, the missing flanking nucleotides were added to each of these marker sequences from a known sequence (accession \# AB212834). The detailed secondary and 3D structures of the modeled proteins were analyzed with software PDBsum, UCSF chimera 1.11.2 and Discovery Studio V3.1.

\section{RESULTS AND DISCUSSION}

Sequence analysis of THCA synthase marker in Pakistani cannabis. Kojoma et al. (2006) analyzed cannabinoids (THCA and CBDA) by HPLC in mature leaves of $C$. sativa strains. On the basis of THCA content, cannabis strains have been divided into two groups' drug type (with high THCA content) and fiber type (with low or no THCA content). Furthermore, they were also successful in identification of a THCA synthase sequence-based DNA marker exclusively found in drug type strains. In case of the present study, the specific THCA-synthase marker $(1.2 \mathrm{~kb})$ was retrieved from all the DNA samples of Pakistani cannabis $(\mathrm{O}, \mathrm{S}, \mathrm{K}, \mathrm{L} 1$ and L4); thereby confirming all five to be drug-type in nature. The PCR products were sequenced and accessioned effectively (LC378399, LC378398, LC378397, LN998182 and LC378400).

In the previous studies it has been noted that there exist some significant single nucleotide polymorphisms, (a total number of $62 \mathrm{SNPs}$ ) between the drug type and fiber type THCA synthase gene sequences (Kojoma et al., 2006). Similarly, multiple sequence alignment of the marker sequences understudy and the wellrecognized THCA synthase gene sequences belonging to exotic cannabis plants (Czech, Iran, Mexica, Japan, France, Germany Hungary, Italy and Poland), also unraveled the presence of those landmark SNPs in our isolates which are specific to drug-type strains (Figure 2). However, two nucleotide substitutions were exclusive to Pakistani isolates, i.e. A at positions 851 and $\mathrm{A}$ at position 883 were replaced with $\mathrm{T}$ and $\mathrm{C}$, respectively (Figure 2). The identified markers were about $99.8 \%$ identical to the drug-type THCA synthase genes and $95.8 \%$ to that of fibertype strains. Interestingly, the same percentage of homology (approximately 96\%) occurs between the markers obtained from Pakistani isolates and the fiber type THCA synthase gene sequences representing varying populations of the world. Moreover, the sequences of the individual markers obtained from the five cannabis isolates of Pakistani origin were $100 \%$ identical to one and other (O, S, K, L1 and L4). The phylogenetic dendrogram constructed on the basis of multiple sequence alignment of all the sequences revealed 
that the sequences diverged into two distinct groups at the genetic distance of 2.1. Group I consisted of all the previously documented drug type THCA synthase genes as well as markers of Pakistani isolated, while group II comprised of all the known fiber type THCA synthase genes (Figure 3). All these findings reestablished the association of the observed markers with THCA synthase gene of drug type cannabis.

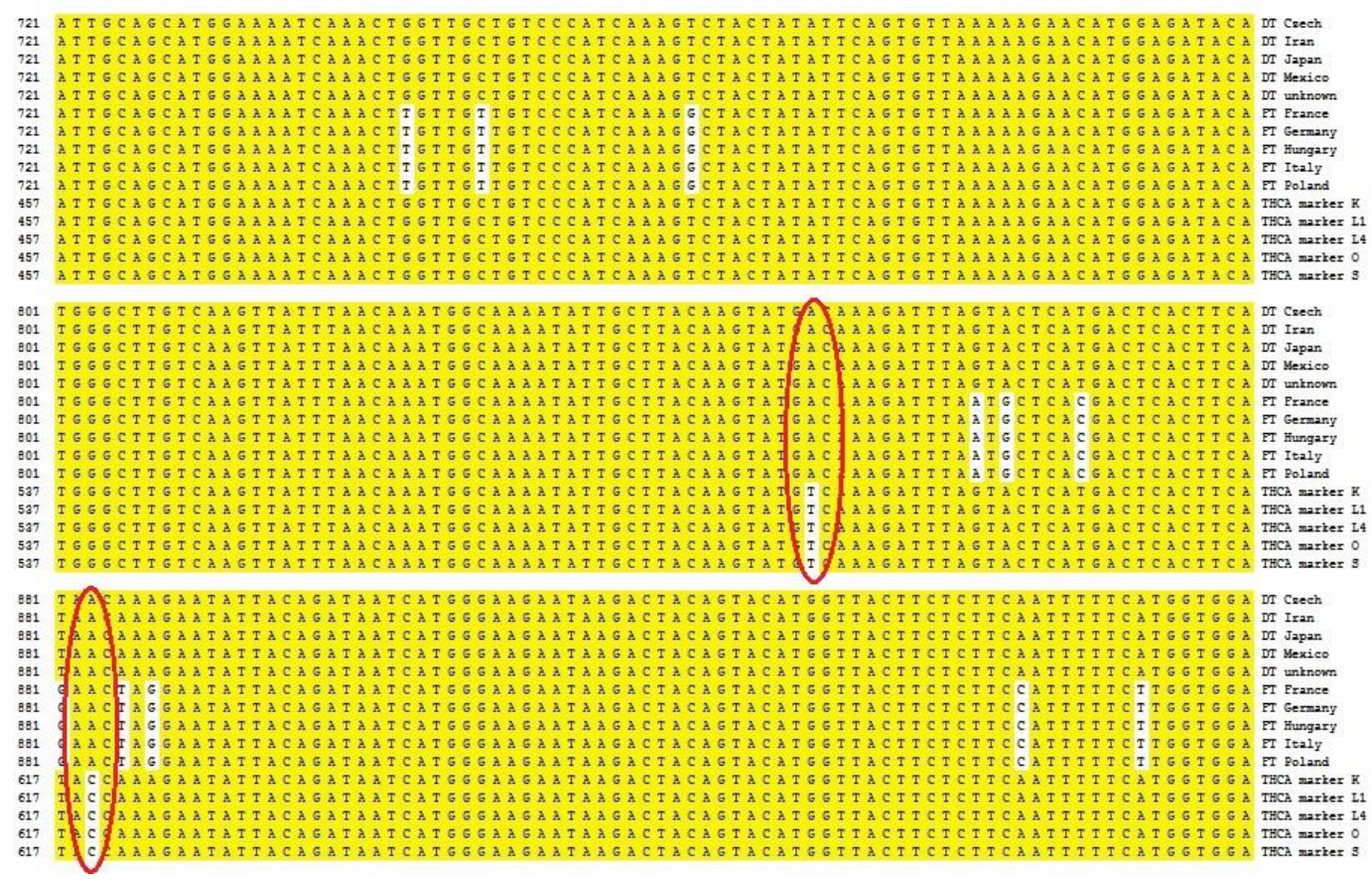

Figure 2. Alignment of the 'drug type' THCA synthase marker sequences isolated from Pakistani cannabis with the reported coding region of THCA synthase gene belonging to different areas of the world. 'DT' represents reported 'drug type'; 'FT' indicates reported 'fiber type' gene sequences; and sequences from K to $S$ represent THCA marker sequences of Pakistani cannabis. The red circles highlight the two SNPs $(\mathrm{A} \rightarrow \mathrm{T}$ and $\mathrm{A} \rightarrow \mathrm{C})$ in the sequence of Pakistani cannabis.

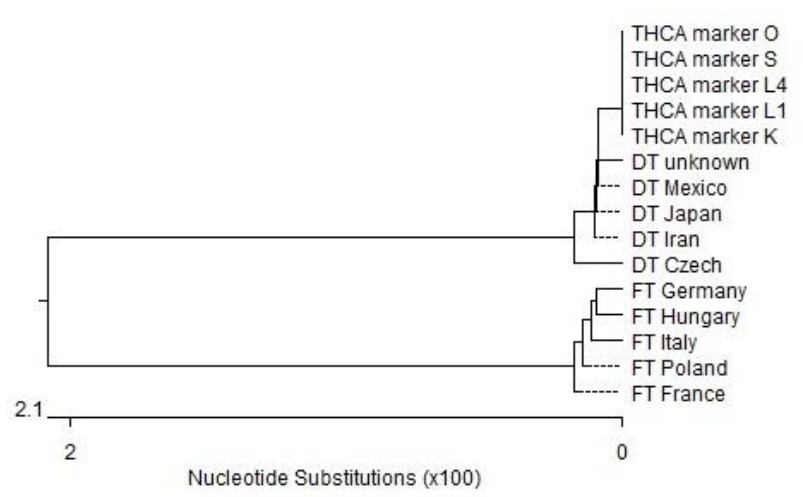

Figure 3. Phylogenetic tree based on multiple sequence alignment of isolated and reported THCA synthase gene sequence. The two main groups diverged at 2.1 genetic distance; all the known 'fiber type' related sequences (FT) constitute one cluster; while the 'drug type' related sequences (DT) make a separate cluster including the THCA marker sequences isolated from Pakistani cannabis (O, S, L4, L1 \& K).
Prediction of THCA protein sequence. After the discovery of two single nucleotide substitutions in THCA synthase fragment of Pakistani cannabis, it was imperative to find out if these mutations are merely silent or they do have a considerable impact on the sequence, structure and function of the translated protein (Raamsdonk et al., 2001). The task at hand was achieved by translating and analyzing the sequences using software designated for each purpose. Since the marker sequences $(\mathrm{O}, \mathrm{S}, \mathrm{K}, \mathrm{L} 1$ and L4) being studied are $100 \%$ identical to one another, only one isolate L1 was selected as a representative sequence for Pakistani gene pool. Likewise, one representative of each known drug type and fiber type THCA synthase gene was picked to perform the comparative study of the predicted amino acid sequences. The original number of the amino acids constituting THCA synthase is 545 ; however, none of the translated proteins except that of reported drug type and 
fiber type gave complete sequence of THCA synthase (409 amino acids) as the amplified fragments were partial gene sequences (Sirikantaramas et al., 2004). Twenty-seven of the amino acid substitutions detected formerly in fiber type plants were absent in Pakistani hemp, hence reinstating the assumption that the obtained isolates were in fact drug type (Kojoma et al., 2006). It was also noticed that the two nucleotide substitutions specific to Pakistani drug type cannabis encoded amino acids different from that of published THCA synthase sequences i.e., valine (V) was replaced with aspartic acid (D) at position 284 and threonine ( $\mathrm{T}$ ) at position 295 was substituted by proline (P) (Figure 4). Thus, the two mutations are considered non-synonymous which means that the change in a single amino acid is a direct result of a single nucleotide substitution (Kumar et al., 2009).

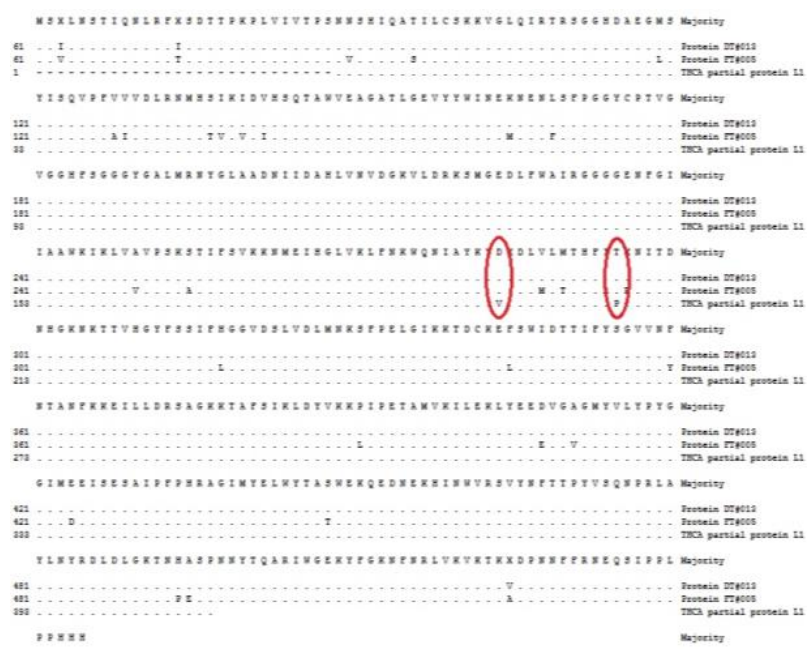

Figure 4. Multiple sequence alignment of predicted protein sequences of THCA synthase gene. 'Protein DT' shows one representative of reported 'drug type' THCA synthase (accession \# AB212834); 'Protein FT' indicates a representative amino acid sequence of fiber type protein (accession \# AB212830); and 'partial L1 protein' stands for the predicted protein sequence of one representative of Pakistani THCA synthase gene (accession \# LN998182). The red circles highlight the two amino acid substitutions $(\mathrm{D} \rightarrow \mathrm{V}$ and $\mathrm{T} \rightarrow \mathrm{P}$ ) in the putative protein of Pakistani cannabis.

In order to ascertain whether the identified SNPs in our isolated marker lied in the conserved domains of the protein or not, the sequences were analyzed using NCBI's conserved domain (CDD) search (Marchler-Bauer et al., 2014). Consequently, two main domains were recognized in the THCA synthase protein, i.e. FAD-binding domain and berberine \& berberine like domain spanning amino acids 81 to 218 and 480 to 538, respectively (Figure 5) (Daniel et al., 2017). Similar domains were discerned in the predicted THCA synthase protein of Pakistani cannabis (Figure 5). Based on this outcome, it became clear that the two mutations (Val284 and Pro295) indicated in the current study were not located inside the highly conserved regions of the protein sequence.

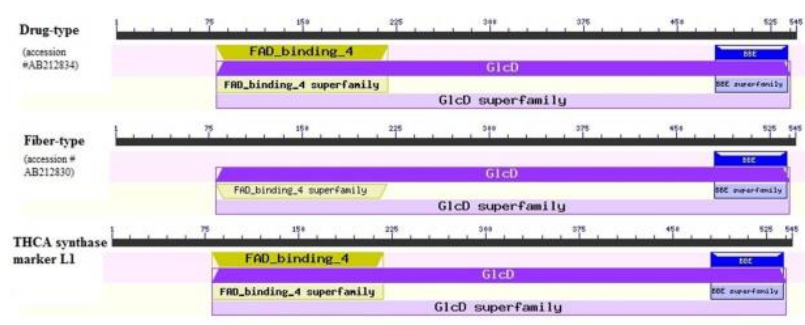

Figure 4. Conserved domain database search for one representative of predicted THCA synthase protein sequence of known drug-type, known fiber-type and Pakistani cannabis (L1) each. 'FAD binding domain' is indicated in drug type and Pakistani cannabis proteins starting from position 81 and ending at position 218.

Comparison of predicted $3 D$ structures of the obtained sequences. The resultant models (DT, FT and L1) were assessed for their authenticity and quality by comparing them with the template (3VTE) structure. Each of the modeled targets, i.e. DT (Accession \# AB212834), FT (Accession \# AB212830) and L1 (Accession \# LN998182) are presented in the current study (Figure 6, Fig. $3 a, 4 a$, and 5a; Supplementary Material). According to the results, the error values for residues turned out to be quite insignificant as determined by ERRAT; the quality factor for the generated structures ( 93.5 to 93.7 ) was very much analogous to that of the template (92.81). Similar quality factor of ERRAT was noted by El Alaoui et al. (2014) in 3VTE (Table 1). In addition, the $z$ score of the THCA synthase proteins under scrutiny laid further emphasis on the proximity of these models with the scientifically proven X-ray and NMR structures of similar sized proteins (Biasini et al., 2014). The structures understudy had $z$-score values $(-10.51$ to -10.28$)$ which were 
quite comparable to the $\mathrm{z}$-score of templates (9.26). Hence, the above evidence was authentic enough to establish the validity of the target THCA synthase models. Likewise, the z-score of 3VTE estimated in another study was also -9.26 (El Alaoui et al., 2014) (Table 1).

RMSD values for the generated models were calculated in reference to the template so as to highlight the legitimacy of the structures. The RMSD values fell within the range of $0.127 \AA$ to $0.507 \AA$ which is supposed to be less than $3 \AA$ for closely related proteins (Reva et al., 1998) (Table.1). Additionally, RAMPAGE was utilized for the assessment of Ramachandran plots created for each model as well as the template. The percentage of residues in favored regions for the studied structures ranged from $93.2 \%$ (FT) to $93.8 \%$ (DT \& L1), equivalent to that of template i.e. $92.5 \%$. Similarly, the residues in allowed regions were $5.2 \%$ in DT and L1, $2 \%$ in FT and $7.1 \%$ in 3 VTE (Table. 2). On the other hand, the outlier regions contained $1.0 \%$ of residues for DT and $\mathrm{L} 1 ; 0.8 \%$ residues for FT; $0.4 \%$ amino acids for template (Table 2). The secondary structures of the obtained structures were aligned with the template THCA synthase via superimposition of all the proteins (Figure 7). Docking of the ligands CBGA (canabigerolic acid) for the modeled proteins and 3VTE was performed using SwissDock and analyzed with UCSF Chimera and discovery studio (Grosdidier et al., 2007). The binding energy scores were found to be -7.16 $\mathrm{kcal} / \mathrm{mol}$ and $-7.03 \mathrm{kcal} / \mathrm{mol}$ for $3 \mathrm{VTE}$ and DT (drug type), respectively. In case of L1 (Pakistani THCA synthase), the energy of binding lied within the same range i.e. $-6.84 \mathrm{Kcal} / \mathrm{mol}$; strengthening the hypothesis that the isolated sequences were in fact drug type (El Alaoui et al., 2014). On the contrary, the fiber type protein (FT) selected for this study showed binding energy equaling $-5.05 \mathrm{Kcal} / \mathrm{mol}$ in value, supporting the assumption that the drug type THCA synthase carries higher affinity for CBGA molecules than the fiber type enzyme. According to one estimate the amount of THCA synthesized in drug type may reach up to 4.1 percent while the quantity of THCA in fiber type does not go beyond 0.2 percent (Shirota et al., 1998). The elevated content of THCA in drug type can be attributed to the greater affinity of its enzyme for CBGA (Shoyama et al., 2012).
The residues at the active-site of the computed THCA synthase models were determined adequately; His114 and Cys176 seemed to play the most predominant role in FAD binding (Figure 8), while Tyr175, Tyr417 and Tyr484 were supposedly the main participants in the binding of CBGA (Figure 9). Shoyama et al. (2012) and El Alaoui et al. (2014) had reached the same conclusion regarding the catalysis of THCA.

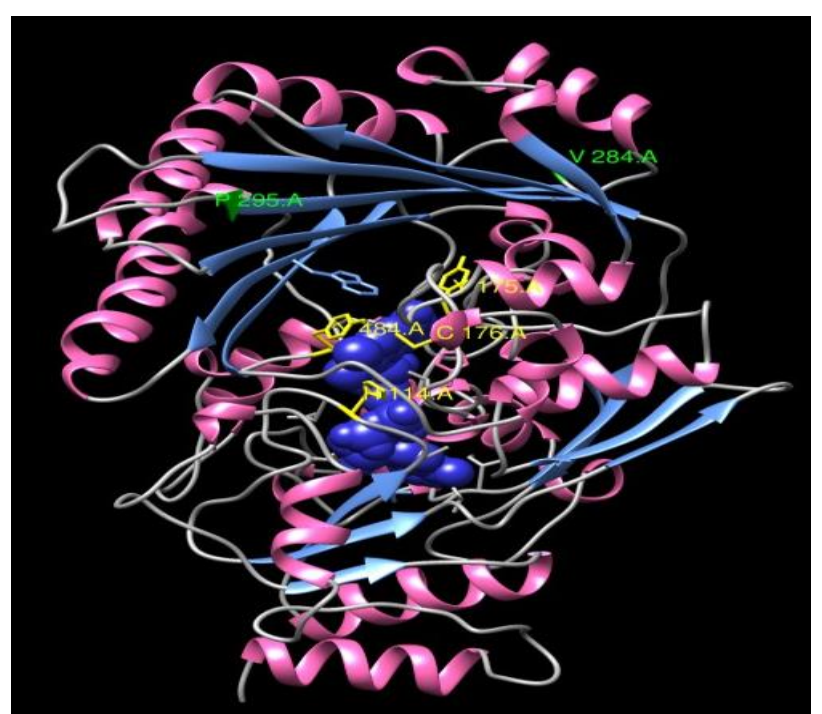

Figure 5: Predicted 3D structure of the putative THCA synthase protein L1 (accession \# LN998182) identified in Pakistani cannabis, modeled using Swiss Model and observed with UCSF Chimera. The blue molecule shows the ligand FAD; the green amino acids (Val284 \& Pro295) are the substitutions observed only in Pakistani cannabis; and the yellow residues indicate the key amino acids at active site of the enzyme i.e. Tyr175, Cys176, Tyr484 \& His114.

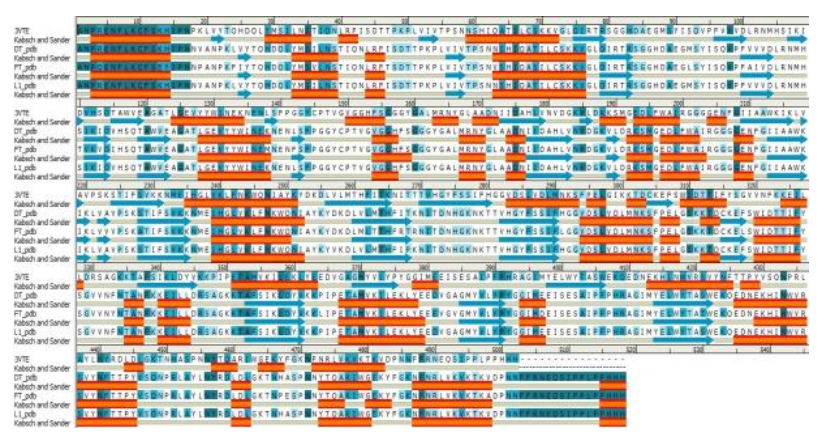

Figure 6. Secondary structure alignment of the modeled Pakistani protein 'L1' with the modeled known 'drug type' and 'fiber type' THCA synthase as well as template ' 3 VTE'. The dark blue color highlights the preserved amino acids in all sequences; orange bands represent $\alpha$-helices; and $\beta$-sheets are given as blue pointers 


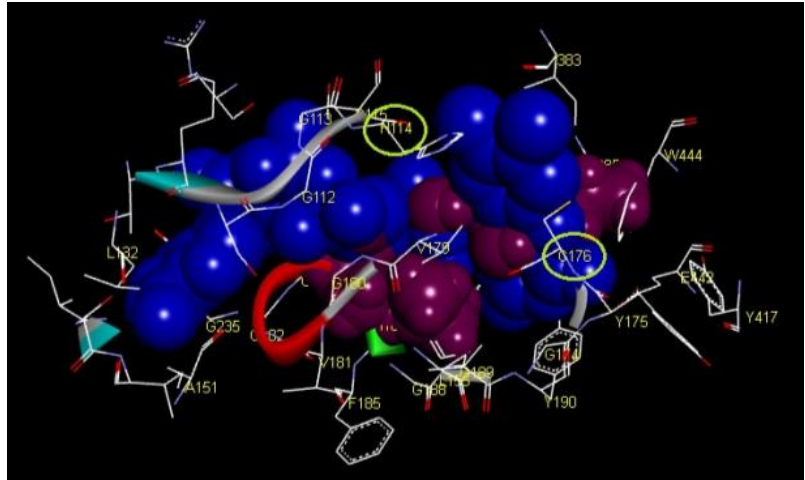

Figure 7. Putative active site of CBGA and FAD in the predicted/modeled THCA synthase protein 'L1' isolated from Pakistan; showing an angle which depicts the proximity of His114 and Cys176 to FAD (inside yellow circles).

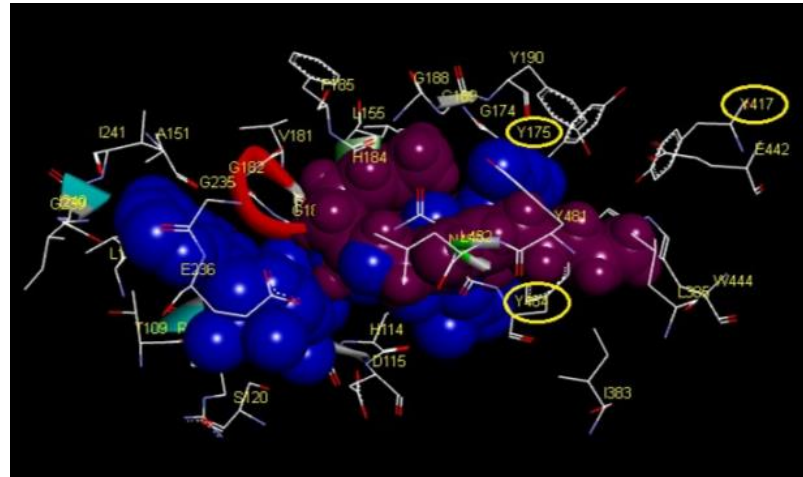

Figure 8. Putative active site of CBGA and FAD in the predicted/modeled THCA synthase protein 'L1' isolated from Pakistan; showing an angle which depicts the proximity of Tyr175, Tyr417 and Tyr484 to CBGA (inside yellow circles).

Table 1. General attributes of the modelled protein structures and RMSD values of the models aligned against template 3VTE.

\begin{tabular}{|c|c|c|c|c|c|c|c|c|}
\hline \multirow[b]{2}{*}{ Protein } & \multirow[b]{2}{*}{ ID } & \multirow[b]{2}{*}{ Z-score } & \multirow[b]{2}{*}{ Verify $\%$} & \multirow[b]{2}{*}{ ERRAT } & \multicolumn{4}{|c|}{ RMSD A } \\
\hline & & & & & $\begin{array}{c}\text { C- } \\
\text { Alpha }\end{array}$ & $\begin{array}{l}\text { Main- } \\
\text { chain }\end{array}$ & $\begin{array}{l}\text { Side- } \\
\text { chain }\end{array}$ & $\begin{array}{c}\text { All } \\
\text { protein }\end{array}$ \\
\hline $\begin{array}{c}\text { Template } \\
\text { THCA synthase }\end{array}$ & $\begin{array}{l}\text { PDB: } \\
\text { 3VTE }\end{array}$ & -9.26 & 95.23 & 92.813 & - & - & - & - \\
\hline $\begin{array}{c}\text { Drug-type } \\
\text { THCA synthase } \\
\text { (DT) }\end{array}$ & $\begin{array}{l}\text { Accession: } \\
\text { AB212834 }\end{array}$ & -10.51 & 95.56 & 93.491 & 0.147 & 0.222 & 0.443 & 0.352 \\
\hline $\begin{array}{l}\text { Fiber-type } \\
\text { THCA synthase } \\
\text { (FT) }\end{array}$ & $\begin{array}{l}\text { Accession: } \\
\text { AB212830 }\end{array}$ & -10.28 & 97.88 & 93.700 & 0.127 & 0.211 & 0.507 & 0.388 \\
\hline $\begin{array}{c}\text { Pakistani } \\
\text { THCA synthase } \\
\text { (L1) }\end{array}$ & $\begin{array}{l}\text { Accession: } \\
\text { LN998182 }\end{array}$ & -10.37 & 95.56 & 93.491 & 0.146 & 0.220 & 0.444 & 0.352 \\
\hline
\end{tabular}

Table 2. Ramachandran plot data computed by RAMPAGE, a good quality model would be expected to have over $90 \%$ in the most favoured regions.

\begin{tabular}{ccccc}
\hline Protein & ID & $\begin{array}{c}\text { Residues in } \\
\text { favoured } \\
\text { region }\end{array}$ & $\begin{array}{c}\text { Residues in } \\
\text { allowed } \\
\text { region }\end{array}$ & $\begin{array}{c}\text { Residues in } \\
\text { outlier region }\end{array}$ \\
\hline Template THCA synthase & PDB: 3VTE & $92.5 \%$ & $7.1 \%$ & $0.4 \%$ \\
Drug-type THCA synthase (DT) & Accession: AB212834 & $93.8 \%$ & $5.2 \%$ & $1 \%$ \\
Fiber-type THCA synthase (FT) & Accession: AB212830 & $93.2 \%$ & $6.0 \%$ & $0.8 \%$ \\
Pakistani THCA synthase (L1) & Accession: LN998182 & $93.8 \%$ & $5.2 \%$ & $1 \%$ \\
\hline
\end{tabular}

\section{CONCLUSION}

In this study, we isolated a DNA marker linked with THCA synthase of drug type cannabis from 5 isolates of Pakistan. The DNA sequence of the obtained marker was compared with the reported sequences of the enzyme (THCA synthase) belonging to different regions of the world. It was found that the identified sequences were highly identical $(99.8 \%)$ to the sequence of drug type THCA synthase with the exception of only 2 nucleotides which were specific to only Pakistani cannabis. Moreover, the protein sequence 
prediction of the sequences showed that the 2 variations also got translated into two amino acid substitutions. However, the changes in amino acid sequence did not apparently affect the structure of the protein, nor did it influence its affinity to the substrate (CBGA) as revealed by the homology modeling of the putative protein sequences. The analysis of FAD/CBGA binding pocket also showed the presence of similar residues at active site as indicated in earlier studies. The detection of two nucleotide mutations as well as two amino acid substitutions in 'drug type' Pakistani cannabis will help point to the identification of cannabis plant being illegally transported from Pakistan to other countries and will greatly aid forensic studies.

\section{ACKNOWLEDGEMENT}

We are grateful to all the members of Plant Biotechnology lab of School of biological sciences for helping us out in every way possible.

\section{REFERENCES}

Alghanim, H. J. \& Almirall, J. R. 2003. Development of microsatellite markers in Cannabis sativa for DNA typing and genetic relatedness analyses. Analytical and Bioanalytical Chemistry 376(8): 1225-1233.

Baker, P. B., Gough, T. A., \& Taylor, B. J. 1982. The physical and chemical features of Cannabis plants grown in the United Kingdom of Great Britain and Northern Ireland from seeds of known origin. Bulletin on Narcotics 34(1): 27-36.

Biasini, M., Bienert, S., Waterhouse, A., Arnold, K., Studer, G., Schmidt, T., Kiefer, F., Cassarino, T. G., Bertoni, M., Bordoli, L., \& Schwede, T. 2014. SWISS-MODEL: modelling protein tertiary and quaternary structure using evolutionary information. Nucleic Acids Research 42(1): 252258.

Daniel, B., Konrad, B., Toplak, M., Lahham, M., Messenlehner, J., Winkler, A., \& Macheroux, P. 2017. The family of berberine bridge enzyme-like enzymes: A treasure-trove of oxidative reactions. Archives of Biochemistry and Biophysics 632: 88-103.

de Meijer, E. P., Bagatta, M., Carboni, A., Crucitti, P., Moliterni, V.C., Ranalli, P., \& Mandolino, G. 2003. The inheritance of chemical phenotype in Cannabis sativa L. Genetics 163(1): 335-346.

El Alaoui, M. A., Ibrahimi, A., Semlali, O., Tarhda, Z., Marouane, M., Najwa, A., Soulaymani, A., \& El Fahime, E. 2014. Affinity comparison of different THCA synthase to CBGA using modeling computational approaches. Bioinformation 10(1): 33.

Gigliano, G. S. 1995. Restriction profiles of trnL (UAA) intron as a tool in Cannabis Sativa L. identification. Delpinosa 37: 85.
Gillan, R., Cole, M. D., Linacre, A., Thorpe, J. W., \& Watson, N. D. 1995. Comparison of Cannabis sativa by random amplification of polymorphic DNA (RAPD) and HPLC of cannabinoids: a preliminary study. Science \& justice: Journal of the Forensic Science Society 35(3): 169-177.

Gilmore, S., Peakall, R., \& Robertson, J. 2003. Short tandem repeat (STR) DNA markers are hypervariable and informative in Cannabis sativa: implications for forensic investigations. Forensic Science International 131(1): 65-74.

Grosdidier, A., Zoete, V., \& Michielin, O. 2007. EADock: docking of small molecules into protein active sites with a multiobjective evolutionary optimization. Proteins: Structure, Function, and Bioinformatics 67(4): 1010-1025.

Hsieh, H. M., Hou, R. J., Tsai, L. C., Wei, C. S., Liu, S. W., Huang, L. H., Kuo, Y. C., Linacre, A., \& Lee, J. C. I. 2003. A highly polymorphic STR locus in Cannabis sativa. Forensic Science International 131(1): 53-58.

Jagadish, V., Robertson, J., \& Gibbs, A. 1996. RAPD analysis distinguishes Cannabis sativa samples from different sources. Forensic Science International 79(2): 113-121.

Kojoma, M., Iida, O., Makino, Y., Sekita, S., \& Satake, M. 2002. DNA fingerprinting of Cannabis sativa using inter-simple sequence repeat (ISSR) amplification. Planta Medica 68(01): 60-63.

Kojoma, M., Seki, H., Yoshida, S., \& Muranaka, T. 2006. DNA polymorphisms in the tetrahydrocannabinolic acid (THCA) synthase gene in "drug-type" and "fiber-type" Cannabis sativa L. Forensic Science International 159:132-140.

Kumar, P., Henikoff, S., \& Ng, P. C. 2009. Predicting the effects of coding non-synonymous variants on protein function using the SIFT algorithm. Nature Protocols 4(7): 1073.

Marchler-Bauer, A., Derbyshire, M. K., Gonzales, N. R., Lu, S., Chitsaz, F., Geer, L. Y., Geer, R. C., He, J., Gwadz, M., Hurwitz, D. I., \& Lanczycki, C. J. 2014. CDD: NCBI's conserved domain database. Nucleic Acids Researcb 43(1): 222-226.

Miller, H. C., Shutler, G., Abrams, S., Hanniman, J., Neylon, S., Ladd, C., Palmbach, T., \& Lee, H. C. 2003. A simple DNA extraction method for marijuana samples used in amplified fragment length polymorphism (AFLP) analysis. Journal of Forensic Sciences 48(2): 343-347.

Miyahara, M., Sugaya, K., Tanimura, A., \& Satake, M. 1998. Nucleotide sequences of 5S-rRNA gene spacer region of Moraceae and Cannabaceae. Natural Medicine 52(3): 209-212.

Quimby, M. W., Doorenbos, N. J., Turner, C. E., \& Masoud, A. 1973. Mississippi-grown marihuana-Cannabis sativa cultivation and observed morphological variations. Economic Botany 27(1): 117-127.

Raamsdonk, L. M., Teusink, B., Broadhurst, D., Zhang, N., Hayes, A., Walsh, M. C., Berden, J. A., Brindle, K. M., Kell, D. B., Rowland, J. J., \& Westerhoff, H. V. 2001. A functional genomics strategy that uses metabolome data to reveal the phenotype of silent mutations. Nature Biotechnology 19(1): 45.

Reva, B. A., Finkelstein, A. V., \& Skolnick, J. 1998. What is the probability of a chance prediction of a protein structure with an rmsd of 6 A?. Folding and Design 3(2): 141-147.

Rowan, M. G. \& Fairbairn, J. W. 1977. Cannabinoid patterns in seedlings of Cannabis sativa L. and their use in the determination of chemical race. Journal of Pharmacy and Pharmacology 29(1): 491-494.

Shirota, O., Watanabe, A., Yamazaki, M., Saito, K., Shibano, K., Sekita, S., \& Satake, N. 1998. Random amplified polymorphic DNA and restriction fragment length polymorphism analyses of Cannabis sativa. Natural Medicines 52(2): 160-166.

Shoyama, Y., Tamada, T., Kurihara, K., Takeuchi, A., Taura, F., Arai, S., Blaber, M., Shoyama, Y., Morimoto, S., \& Kuroki, R. 2012. Structure and Function of $\Delta 1$ - 
Tetrahydrocannabinolic Acid (THCA) Synthase, the Enzyme Controlling the Psychoactivity of Cannabis sativa. Journal of Molecular Biology 423(1): 96-105.

Sirikantaramas, S., Morimoto, S., Shoyama, Y., Ishikawa, Y., Wada, Y., Shoyama, Y., \& Taura, F. 2004. The Gene Controlling Marijuana Psychoactivity Molecular cloning and heterologous expression of $\delta 1$-tetrahydrocannabinolic acid synthase from Cannabis Sativa 1. Journal of Biological Chemistry 279(38): 39767-39774.

Small, E. \& Cronquist, A. 1976. A practical and natural taxonomy for Cannabis. Taxon 25(4): 405-435.

Taura, F., Morimoto, S., Shoyama, Y., \& Mechoulam, R. 1995. First direct evidence for the mechanism of $\Delta^{1}$ Tetrahydrocannabinolic acid biosynthesis. Journal of the American Chemical Society 117(38): 9766-9767. 